The Research Journal of the Costume Culture

[Original Article]

Received November 16, 2016 Accepted February 22, 2017

${ }^{\dagger}$ Corresponding author

(taemik@naver.com)

ORCID

Taemi Kim

http://orcid.org/0000-0001-7065-1499

chulhyun cho

http://orcid.org/0000-0002-4028-7101

\section{A qualitative study on the clothing behavior of visually impaired people}

\author{
Taemi $\mathrm{Kim}^{\dagger}$ and Chul Hyun Cho*
}

Dept. of Fashion Material, Korea Polytechnics, Korea Vocational Training Division, Ministry of Justice, Korea ${ }^{*}$

\section{시각 장애인의 의복행동에 대한 질적 연구}

\author{
김 태 미 ${ }^{\dagger} \cdot$ 조 철 현 \\ 한국폴리텍대학섬유패션캠퍼스 패션소재과 \\ 법무부 직업훈련과
}

\begin{abstract}
The purpose of this study was to examine visually impaired people's clothing behavior, using a qualitative approach. The results are intended to be used as baseline data to make an instrument that can measure the factors that have an effect on visually impaired people's clothing needs from the perspective of environmental and social relationship contexts. This study was made through in-depth interviews with people with grade-1 visual impairment, and the results were as follows: First, when purchasing clothing, they were accompanied by trusted people, and chose trusted brands and trusted products. They spent as little time as possible, did not try on many clothes, and they preferred colors, designs, and purchase methods that carried as low a risk as possible. Second, they wanted basic product information and simple procedures when purchasing and using clothing products. Third, they were able to manage their own clothes themselves. However, there was insufficient laundry information available. Fourth, the main reason why visually impaired people took care of their appearance was that they wanted to look neat and clean to be respected by others. Based on the study results, it is necessary to provide information on clothing to improve quality of life and welfare and thus ensure visually impaired people's independence.
\end{abstract}

Keywords: visually impaired(시각 장애인), clothing behavior(의복행동), qualitative approach (질적연구)

\section{Introduction}

2015년 보건복지부 통계자료에 의하면 등록된 시각 장애인은 25 만 명을 넘어섰 으며, 현재 시각 장애인의 $90 \%$ 는 질환과 사고로 인한 후천적인 원인으로 시각 장애 를 겪고 있다. 시각장애인 중 $88 \%$ 는 저시력 장애인으로 잔존 시력을 가지고 있다 (Oh et al., 2016). 또한, 장애인 등급 판정을 받지는 않았지만, 노화와 질병, 업무의 
특성 등으로 인해 일상생활에서 시각 장애를 가지는 이들도 날로 증가함에 따라 시각 장애로 인한 다양한 문제들이 발생하고 있으며, 이들에 대한 사회적 관심 과 복지에 대한 연구가 진행되어감에 따라 장애인 복 지의 패러다임은 재활에서 자립생활로 바뀌어, 이제 장애인 개인의 문제가 아니라, 사회 전반적인 통제기 제를 포함하는 환경에 대한 문제로 인식되고 있다(Kim, 2005). 최근 발표된 선천적 시각 장애인과 청안자들 이 인식하는 색채어휘의 특징에 대한 비교연구(Shin \& Ohmi, 2012)에서는 시각 장애인들의 색채 어휘의 특징에 대해 높은 인식률을 가지고 있는 것으로 나타 났으며, 시각 장애인을 위한 컬러인식 점자 시스템도 개발(Ahn \& Lee, 2007)되는 등 시각 장애인들의 시 각적 인지와 관련된 연구들이 이루어지고 있다.

욕구란 개인의 구매의사 결정과 소비 사이클에 영 향을 주는 중요 요인으로, 개인이 의복을 통해 충족 시키고자 하는 총체적인 욕구를 의복욕구라고 정의 할 수 있다. 현대인의 의복 욕구는 기본 욕구의 충족 을 얻어 자기 정체성을 표현하고, 쾌락과 체험을 추 구하므로 의복욕구는 개인의 심리적인 만족과 이를 위해 구체적인 선택을 포괄하는 개념으로 다차원적 이고 총체적으로 파악하여야 한다(Kim \& Rhee, 2008). Maslow는 욕구 5단계 이론에서 인간은 생존을 위한 의식주와 같은 1 단계의 “생리적 욕구"가 충족되면, 2 단계로 몸을 안전하게 보호하기 위한 욕구를 갈망하 고, 이 “안전 욕구"가 충족되면, 3 단계에서의 사회적 관계 속에서 “사랑과 소속감의 욕구”를 추구한다고 하였다. 그리고, 이 욕구가 충족되면 다시 윗 단계인 4단계의 자아상에 대한 인정을 받기 위한 “존중 욕 구"를 실현하고자 하고, 이 존중 욕구가 실현되면, 5 단계의 자아실현을 갈망하는 “자아실현욕구”가 발현 된다고 하였다(Kang, 1995). 의복은 1단계의 생리적 욕구에서부터 5 단계의 자아실현의 욕구까지 각 단계 의 욕구들과 밀접한 관계를 지니고 있다. 즉, 의복은 시각적 자아를 완성시키는 대표적인 제품으로 인간 의 생리와 안전 추구라는 기본적인 욕구뿐 아니라, 사 랑과 소속감, 존중과 자아실현과 같은 다양한 심리적 욕구와 사회적 욕구를 충족시킨다. 또한, 의복은 선, 재질, 색채, 디테일 등의 다양한 조합으로 이루어지는 제품으로 상징적 의미와 더불어 소비자 개인의 자아 를 형성하고, 정체성을 표현하며, 다양한 욕구가 표출
되는 도구이다.

의복행동에는 의복에 대한 개인의 욕구에 못지않 게 개인에 작용하는 환경적 또는 사회적 환경이 개인 의 욕구에 작용한다. 왜냐하면 의복관련 행동은 본질 적으로 일종의 사회적 행동이고, 사회적 행동에는 문 화적, 경제적, 사회적 영향이 직접적 또는 간접적으로 작용하기 때문이다. 또한, 개개인이나 집단이 가지는 자아 존중감과 주변관계와의 만족 정도가 의복행동 의 특성에 나타난다고 볼 수 있다(Kim \& Choi, 2011). 아름답고 편안한 옷, 소속감을 표출하고 남들에게 인 정받을 수 있는 옷차림을 하고자 하는 것은 인간이 가지는 기본적인 욕구이다. 그러나 우리 사회는 시각 장애인들이 보이지 않는다는 선입견의 전제하에 이 들에 대한 시각적인 인지에 대한 연구는 부족하며, 이 들의 기본적인 의복욕구를 기반으로 시각 장애인들의 의복생활에 대한 심층적인 연구는 미비한 실정이다.

이에 본 연구의 목표는 일차적으로 시각 장애자들 이 가지는 의복행동의 특성에 대해 알아보기 위해 심 층 인터뷰를 통한 질적 연구를 하고자 한다. 이를 통 해 그동안 미미하게 진행되어 오던 시각 장애자들의 의복연구에 대한 기초자료로서의 활용하고자 한다.

\section{Background}

\section{Visually impaired persons}

인간이 가지는 감각 기능 중 시각에 장애가 있는 사 람들을 시각 장애인이라고 하며, 시각 장애는 그 시력 의 정도에 따라 등급으로 구분할 수 있다. 장애인복지 법에 따르면 시각 장애인은 만국식 시력표에 따라 측 정된 교정시력이 나쁜 눈의 시력이 0.02 이하인 사람, 좋은 눈의 시력이 0.2 이하인 사람, 두 눈의 시야가 각 각 주시점에서 10 도 이하로 남은 사람, 두 눈의 시야 2 분의 1 이상을 잃은 사람으로 정의하고 있다.

Lee and $\mathrm{Ye}(2016)$ 가 발표한 전국 시각 장애인의 실태에 대한 연구에 따르면 남성이 여성보다 장애비 율이 높게 나타났으나, 최근 10 년 간 여성 시각 장애 인이 남성에 비해 2 배 정도 더 증가하고 있으며, 이에 대한 이유를 여성의 사회 진출 및 사회 참여 빈도 증 가에 따른 사회환경적인 사고 및 재해로 인한 사고가 증가와 기대 수명의 연장으로 보았다. 또한, 중증 시 각 장애( $17.5 \%)$ 보다 경중장애( $82.5 \%)$ 가 대부분인 것 
으로 나타나, 점차 늘어나는 여성 시각 장애인들과 비교적 낮은 수준의 장애에 대한 세심한 복지지원이 필요할 것이라 보았다.

Shin and Ohmi(2012)는 선천적 시각 장애인에 있 어서의 색채어휘의 특징과 관계성에 대해 알아보기 위해 시각기관을 통한 시각적 경험을 전혀 가지고 있 지 않는 선천적 시각장애인들을 대상으로 이들이 인 식하고 있는 색채의 개념에 대해 연구하였으며, 이를 위해 두 가지를 확인하고자 하였다. 그 첫 번째는 선천 적 시각장애인들이 사용하는 색채어휘의 현상적 특징 을 정량적으로 확인하기 위해 색채어휘를 수집, 분석 함과 동시에 그 결과를 청안자에게서 보여지는 특징 과 비교 검토하는 것이었으며, 두 번째는 색채어 또 는 색명이 어떻게 구조화 되어 인식되어 있는지, 또 그 구조는 청안자에 의해 표현되는 색공간 구성과 어떻 게 대응되는지를 검토하는 것으로, 이를 "색이름에 대한 공간"을 중심으로 고찰한 결과, 선천적 시각장 애인의 색채어휘 인식의 특징으로 11 개의 기본색채 어의에 대해 높은 인식률이 확인하였고, 이에 대해 청안자들의 특징과도 유사한 것을 확인하였다고 발 표하였으며, 이러한 연구결과는 청안자의 특징이 그 대로 학습되었을 가능성이 높은 것으로 볼 수 있다고 하였다. 또한, 색채어 공간의 개념에 있어서는 청안자 와의 특징과 거리가 먼 것을 확인하였으며, 이는 색 에 대해 전혀 인식이 없는 시각 장애인들이라 할지라 고 일정한 수준까지는 색에 대한 인식을 학습을 통해 청안자들과 유사한 정도로 인식이 가능하다는 점을 시사한다.

Ahn and Lee(2007)는 후천적 시각장애인들의 색 인지를 돕기 위해 시각장애인을 위한 컬러 인식 점자 시스템 개발에 대한 연구를 하였으며, 후천적 시각장 애인들의 대다수가 시력을 잃기 전 색을 인지하고 있 었다는 점에 착안한 단순히 색상만 인지할 수 있는 것이 아닌 채도, 명도까지 확인이 가능하도록 한 시 스템을 개발 연구하였으며, 그 결과 총 153 가지의 색 상을 확인할 수 있는 점자의 위치와 돌출 정도만 변 화를 준 단순한 디자인으로 실생활에 쉽게 사용이 가 능한 시스템을 개발하였으며, 이를 각종 의류 및 패 션 소품과 화장품 등에 적용함으로써 시각 장애인들 이 가지고 있는 아름다움에 대한 욕구를 해소하고 개 성을 표출시킴으로써 이들의 소통과 사회생활을 도
울 수 있는 하나의 방법으로 제시하였다.

시각 장애인들 역시 하나의 인격체로서 아름다움 을 느끼고 표현할 수 있어야 하며, 이들도 일반인들 과 동등한 입장에서 문화를 누리고, 사회와 소통하고 자 하는 욕구가 매우 강하다. 특히, 여성 시각 장애인 의 수가 늘어나고 있는 현 시점에서 우리 사회와 인 식에 뿌리박힌 선입견인 시각 장애인들이 볼 수 없으 므로, 시각적 인지와는 무관할 것이라는 편견에서 벗 어나 시각장애인들의 시각적인 부분과 관련된 연구 로부터 관심을 가져야 한다. 진정한 복지와 평등이란 사회적 약자로서의 장애를 가진 이들도 일반인들과 동 등하게 자신을 가꾸고 개성을 연출하며, 자기 정체성 의 표현할 수 있어야 하며, 개인적 생활과 사회적 활 동을 하는 시각 장애자들에 대한 심리적이고 실질적 배려와 사회 참여를 도울 수 있는 다양한 방면에서의 관심과 연구가 적극적으로 필요하다.

\section{Clothes for visually impaired persons}

시대와 지역, 문화의 특성에 따라 변화를 거듭해 오 던 의복은 20 세기에 들어오며 대량생산과 더불어 표 준을 기준으로 하는 다수를 위한 디자인에서 어린이 와 노약자, 장애인과 같이 소외되어오던 소수계층까 지 포함하는 유니버설 디자인으로 발전하고 있다.

Lee and Yoo(2003)는 장애인을 위한 의복의 소재 와 디자인에 대해 위생적이고 쾌적하면서 견고하고 신축성 있는 소재가 적합하므로, 내구성 소재와 신축 성 소재를 혼방하거나 니트 조직을 사용하는 것을 제 안하였으며, 휠체어 사용자를 위해 소매 부분을 덧댄 상의와 앞치마 형태의 덧입는 스커트 디자인을 제안 하였고, 편마비 장애인을 위해 바디스와 소매가 분리 되는 상의 디자인을 제안하였으나, 이 또한 신체적 활 동에 장애를 가지는 지체부자유자들을 위한 디자인 제안이었다.

그 외에 장애인들의 의복에 관한 선행연구들을 살 펴보면 상지 운동 기능 장애인의 착 - 탈의 자립성 연 구(Shin \& Chun, 2011), 지체장애인을 위한 웨딩드레 스 디자인(Lee, 2010), 부목과 목발, 휠체어 사용하는 장애인을 위한 의복디자인(Hong, 2001), 장애인 의복 개발을 위한 현황 분석(Shin, Kim, \& Choi, 1999) 등 과 같이 신체적인 장애를 가진 이들을 대상으로 이들 의 신체적 장애를 중심으로 하는 기능적 측면의 연구 
들이 주로 이루어지고 있으며, 이러한 장애인을 위한 의복은 자기만족이나 자아표현 등의 역할보다는 장 애 부위와 특성에 따라 특별한 사항이 요구되어 유행 보다는 실질적 필요성이 우선시 되었기에, 기존의 장 애인의 의복에 대한 연구는 기능적인 면모에 치중하 였으며, 심미적인 측면은 간과된 의복으로 국한되어 이루어지고 있는 경향을 보인다.

시각 장애인을 위한 의복 연구로는 Kim and Park (2005)이 연구한 스마트 기술을 접목시킨 GPS, 라디 오가 각각 부착된 의복과 골볼 게임 운동복, 본딩 소 재 원피스 및 수납 가능한 의복을 제시한 선행연구가 있으며, 의복 개발을 위해 10 명의 시각 장애인들을 대상으로 시각 장애인들의 요구를 반영한 디자인을 제시하였으나, 이 또한, 시각 장애자를 위한 기능적 의 복으로 의복 시각 장애인들의 실제 의복생활에 대한 심층적 연구 결과는 미비한 실정이다.

최근 방영된 드라마에서 시각 장애를 겪는 여자 주 인공이 손으로 더듬어 가며 화장을 하는 모습이 이슈 가 되었는데, 당시 연기자는 자신의 배역을 위해 시각 장애인들을 연구하였으며, 보이지 않아도 손의 감각 을 이용해 화장을 한다는 것을 알고, 실제적인 연기를 하였다고 하였다. 이렇듯 시각 장애자들은 시력을 온 전히 느낄 수 없음에도 일반인 못지않게 옷과 헤어스 타일, 다양한 악세서리, 화장 등을 통해 미에 대한 욕 구를 표출하고자 하며, 실제 직접 보이지 않아도 화장 하는 방법을 배워서 화장을 하며, 주변의 도움을 받아 서라도 자신이 원하는 옷을 골라 구매를 한다.

현재, 시각 장애인들을 위해 점자를 이용한 홈쇼핑 카탈로그 특허(Korea Patent No. 1020110132473, 2011) 가 출원되어 있으며, 이 선행연구로 시각 장애인들의 제품의 구매정보는 제공이 가능하다고 할 수 있으나, 시각 장애인들이 자신이 구매한 옷의 색상과 실루엣, 소재와 디테일, 액세서리 등을 스스로 확인하여 적절
하게 입을 수 있는 지원 시스템은 아직 미비하다.

아름답고 편안한 옷, 소속감을 표출하고 남들에게 인정받을 수 있는 옷차림을 하고자 하는 것은 인간이 가지는 기본적인 욕구이며, 이러한 의복욕구는 시각적 으로 장애가 있다고 해서 없어지는 것이 아님에도, 시 각장애인의 의복생활을 통한 욕구 충족의 제한성으로 삶의 질이 저하되고 있다. 그럼에도 불구하고, 사회적 인 인식되고 있는 선입견 등으로 인해 이에 대한 연구 는 이루어지지 않고 있다. 따라서, 시각 장애인들이 가 지는 기본적 의복 욕구를 충족시켜 주는 것은 시각 장 애인의 의복생활에 있는 애로사항을 해결함과 동시에 자아와 삶의 질을 향상시키는 방법의 하나이다.

\section{Methods}

질적 연구(Chong \& Lee, 2011)는 관련된 지식이 희박한 영역을 이해하기 위해 수행하기 적합한 연구 방법으로, 본 연구는 그 동안 연구가 미흡했던 시각 장애인들의 의복생활에 대한 현실적 이해를 위한 기 초 지식을 얻기 위한 탐구적 수준의 질적 연구로 설 계 및 수행되었다. 연구를 위해 시각 장애자들이 실 제로 하는 의복행동과 그 특성에 대해 알아보기 위해 심층 인터뷰를 통한 질적 방법을 수행하였으며, 연구 를 위해 선정된 연구대상은 시각장애인 복지기관을 통해 선정된 5 명의 1 급 시각장애인이었다. <Table 1> 은 연구 대상자들의 인구사회학적 배경을 요약한 것 이다. 인터뷰는 개별적으로 실시되었으며, 먼저 연구 의 목적과 취지를 설명하고, 응답자의 솔직한 답변과 협조를 요청하였다.

질적 연구에 있어 연구는 사례의 연구가 아닌 한 개의 사례를 이해하는 것을 목적으로 하며(Stake, 1995/ 2001), 이에 적정한 표본의 수는 연구자가 연구 하고자 하는 목적을 위한 질문의 답을 얻기에 충분한

<Table 1> Demographic characteristics

\begin{tabular}{c|c|c|c|c|c|c}
\hline Case no. & Gender & Age & Grade of impairment & Married state & Occupation & Handicapped \\
\hline 1 & Female & 37 & 1 & Married & O & Congenital \\
\hline 2 & Male & 38 & 1 & Single & O & Acquired \\
\hline 3 & Male & 36 & 1 & Married & O & Acquired \\
\hline 4 & Female & 35 & 1 & Single & O & Acquired \\
\hline 5 & Male & 34 & 1 & Married & O & Congenital \\
\hline
\end{tabular}


지의 여부가 기준이 된다(Merriam \& Tisdell, 2015). 따라서, 본 연구는 시각 장애인의 의복 생활에 대한 이해를 목적으로 하며, 이를 바탕으로 향후 양적 연 구를 지속적으로 실시하고자 한다. 연구를 위한 참가 자의 수는 미리부터 제한을 두지 않고 시작하였으며, 인터뷰를 각각 실시하며 5 명의 인터뷰 사례가 연구자 의 연구 목적에 대한 답을 얻기에 충분하다고 판단하 였다.

본 연구에 참여한 연구 참가자는 남성 3 인과 여성 2 인으로 모두 30 대이며, 대졸 이상의 학력과 직업을 가지고 있었다. 선천적으로 시각 장애를 가진 2 명과 후천적으로 시각 장애를 가진 3 인이었다. 연구 참여 자와의 인터뷰는 2016년 8월 1일부터 8월 25일 사이 에 이루어졌다. 인터뷰는 연구자가 시각 장애인들을 대상으로 의복에 관한 강연 등을 수행한 기존의 경험 을 바탕으로 시각 장애인들과 교류가 있는 관계자를 동반한 상태에서 실시하였다. 질문은 사전에 시각 장 애인 복지 관련 전문가를 통해 내용을 검토하고, 이 를 바탕으로 연구자는 시각장애인의 의복 생활에 대 해 인터뷰를 실시하였으며, 시간은 각각 한 시간 내 외로 실시하였다. 질문은 '예' 또는 '아니오' 라는 대 답이 나오지 않도록 반구조화된 질문으로 하였으며, 모든 면담 내용은 녹음하였다.

질의 내용은 나이, 결혼 여부, 직업 유무, 장애 등 급, 시각 장애 발생 시기와 시각 장애 발생원인 및 의 복생활에 대한 질문으로 이루어졌다. 의복생활에 관 한 질문은 크게 의복구매, 의복행동, 의복관리, 외모 관리에 대한 내용으로 의복구매는 의복 구매방법, 의 복 구매 시 가장 고려하는 점, 의복 구매 시 가장 큰 어려움에 대한 질문, 의복행동은 의복 생활과 관련하 여 가장 불편한 점, 외출 시 의복과 관련된 가장 큰 어려움과 사회활동이나 취업 등에 있어 의복 관련성 에 대해 질문하였으며, 의복관리는 의복의 세탁관리 방법과 의복 세탁관리 시 가장 큰 어려움에 대해 질문 하였고, 외모관리에 대해서는 외모를 관리(꾸미는)하 는 이유, 외모를 관리(꾸미는)를 안하는 이유, 자신의 외모 평가 중 누구의 평가를 가장 중요하게 생각하는 지에 대해 질문하였다.

자료의 분석을 위한 코딩은 개방적 코딩방법을 실 시하였으며, 자료의 분석 방법은 4 단계 분석방법 (Giorgi, 1985/2004)에 따라 실시하였다. 1단계는 '전 체인식(sense of the whole)'으로 개방된 태도로 먼저 각각의 녹취 내용과 녹취록을 반복적으로 읽으면서 참여자들의 의복에 대한 경험과 인식 정도에 대한 전 체적인 느낌을 얻었으며, 2 단계로 '연구자의 학문적 관점에서 현상에 대한 의미단위(meaning units)를 구 분'하기 위해 녹취된 자료들을 여러 번 정독하며, 의 미가 있는 구절이나 문장을 찾아 표시하면서, 3 단계의 ‘의미단위를 학문적 용어로 전환’하는 단계를 통해 반 복적으로 나타나는 주제들을 찾아 개념을 추출하였 다. 마지막 4단계로 '변형된 의미단위들을 구조로 통 합’하기 위해 추출된 개념들을 재검토하고, 개념 간의 관계와 공통적 속성들을 재배치하기 위해 녹취록을 재검토하면서 연구문제를 중심으로 핵심 주제의 개념 들을 찾아나갔다. 이 과정을 반복하면서 주제들이 인 터뷰 내용들을 잘 반영하는지를 확인하여 수정, 보완 하는 과정을 수행하였다. 또한 질적 연구 전문가의 확 인을 거쳐 핵심주제의 객관적 분석에 대해 검증함으 로 연구결과의 타당성을 확보하고, 연구 결과를 제시 하는데 있어서 연구 참여자들은 모두 번호로 처리하 여 연구 참여자들의 익명성을 보장하고자 하였다.

\section{Result and Discussion}

\section{Purchasing clothing}

\section{1) Shopping companion}

신뢰하는 사람과의 동행

시각 장애인들의 의복 구매 시 가장 힘든 점은 색상 이나 디자인 등을 인지의 어려움과 쇼핑을 위한 이동 등의 어려움으로 시각 장애를 겪기 전 색에 대한 정보 를 가지고 있는 후천적 시각 장애인들도 실제 의류의 색상이 자신의 얼굴색 등과 잘 어울리는지 알 수 없어 거의 동반자와 함께 간다고 하였다. 동반하는 사람은 본인의 스타일을 잘 알고, 기존에 소유하고 있는 옷에 대해 잘 알고 있으며, 옷에 대한 감각이 있는 신뢰할 수 있는 사람들로 이들과 동행하여 쇼핑에 대한 조언 을 받으며 구매하였다.

시각 장애인들의 쇼핑 시 동반하는 이들은 시각 장 애인들에게 정보 제공과 함께 구매 의사 결정에 가장 큰 영향을 미치는 이들로 시각 장애인들의 실질적인 구매의 의사 결정에 민감도에 영향이 크다고 볼 수 
있으며, 이는 시각 장애인 집단의 특성상 준거집단의 영향력과 민감도가 매우 큰 것으로 보여진다(Kim, 2006).

“옷을 살 때 보이는 사람과 같이 가죠. 점원들은 옷을 팔기 위해 그냥 예쁘다, 좋다라고만 하기 때 문에 믿을 수가 없어서 그래서 믿을 수 있는 사람 과 갑니다. 주변에서 내가 입은 옷을 보고 예쁘다, 잘 어울린다라고 해주면 그 옷을 살 때 같이 가 준 사람이나 그 옷을 코디해 준 사람과 다음에 함께 가려고 합니다. 내 스타일을 잘 알고 있기 때문이 다. 그런 사람과 함께 가서 설명을 듣고 옷을 만져 보고 그렁게 삽니다."(참여자 1)

"옷을 사러 가기 위해 이동도 해야 하고, 스타일링 도 해야 하고, 옷을 구별해야 하는데, 그러기 위해 서는 누군가의 도움을 받아야 합니다. 그런 도움을 모르는 사람에게 도움을 받기 보다는 나의 신체적 인 특징이나, 나의 옷장에 어떤 옷을 가지고 있는 지 등을 나에 대해 잘 알고 있는 사람과 가고자 합 니다. 꼭 가족이나 활동 보조원이 아니라 하여도 옷에 대한 감각이 있고, 내 스타일을 잘 알아서 잘 골라 줄 수 있는 사람과 갑니다."(참여자 2)

"디자인에서 어려운 건 자기 얼굴색을 몰라서 실 제로 입어 봤을 때 어떤 사람에게 도움을 요청했을 때 단순히 안내만 하는 사람은 나에 대해 잘 모르 기 때문에 잘 알고, 나와 함께 쇼핑에 같이 가 준 지인들과 함께 가게 됩니다. 이건 시각 장애인 뿐 아니라, 일반 사람들도 마찬가지일 거에요. 아무래 도 가족이 가장 많이 동행하는 거 같아요. 가장 일 반적인 것 같아요."(참여자 4)

\section{2) Purchasing information}

\section{○ 실질적이고 꼭 필요한 정보 위주의 제공}

제품 구매시 시각 장애인들이 제공받기를 원하는 정보는 너무 복잡하고 다양한 정보보다는 가장 기본 적이고 실제 사용에서 필요한 정보를 위주로 제공받 기를 원하는 것으로 나타났다. 기본적인 정보로는 시 각적으로 확인하기 힘든 제품의 색상이나 무늬에 대 한 정보와 집에서 옷을 관리할 때 필요한 세탁과 다 림질에 대한 정보를 원하였다.
의류제품의 관리와 관련된 정보제공은 일반적으로 제품에 붙은 케어라벨을 통해 제공되고 있으며, 이 또한 시각적인 기호와 문자방식으로 제공되고 있다. 일반 정안인들은 제품 구매 시 필요한 정보를 판매자 로 부터 제공받지 못하였다고 하여도 이후 제품의 케 어라벨 등을 통해 스스로 확인하여 제품을 관리할 수 있으나, 시각 장애인들의 특성상 제품을 구매 시 정 보를 제공 받지 못한 경우 스스로 시각적으로 확인이 어려울 뿐 아니라, 설혹 구매 시 이를 제공 받았다고 하여도 향후 기억의 소실이나 의복 종류가 많아 분별 이 힘들 경우 시각적인 재확인이 쉽지 않기 때문에 이를 위한 다른 형태의 기본적인 정보 제공이 필요하 다고 보여진다.

"일단은 저는 색상이나 무늬를 확인해야 하는 데, 무늬를 위 아래로 잘못 입으면 정말 이상하죠. 그 래서 적어도 어떤 색상과 무늬가 있는 지의 정보는 확인하고 싶어요."(참여자 2)

"세탁에 있어서도 물 세탁이 가능한지 아닌지에 대 한 정보가 매우 필요해요. 일반 정안인들은 잘 몰라 도 라벨을 보면 알겠지만, 저는 모르기 때문에 세탁 방법이나 다림질 등을 알 수가 없을 때 그냥 세탁 소에 가져다가 줘요."(참여자 3)

"너무 복잡한 정보는 많은 것도 힘들고, 적어도 물 세탁의 여부 정도, 밝은 색인지 어두운 색인지 정 도는 매우 필요한 정보입니다."(참여자 4)

"옷을 판매할 때 옷에 표시를 하게 되면 좋겠다. 사이즈와 색상, 세탁법 등을 알려주면 좋겠다.”(참 여자 5)

\section{3) Considerations of purchasing} 단순화된 목적에 따른 구매

시각 장애인들이 제품 구매시 가장 고려하는 것은 일차적으로 사고자 하는 옷을 입는 목적에 따른 의복 구매였다. 목적에 따른 의복 착용의 목적은 단순화하 여 정장과 캐주얼로 주로 나누어 구매 및 관리를 하 였으며, 정장과 같이 격식을 차리기 위한 옷은 유행 을 타지 않으면서도 착용감이 좋은 지를 고려하였다. 그 반면, 신경을 많이 쓰고, 편하게 입는 캐주얼한 의 복은 어디 옷과도 코디네이션하기에 좋고, 무난한 색 
상과 소재의 옷을 선호하였다.

"옷을 어떤 목적을 사는 지가 가장 중요해요. 격식 을 차려 입는 옷인지, 그냥 편하게 입을 옷인지가 중요해요. 어디에 갈 때 입을 옷인지 평상복인지가 중요해요."(참여자 2)

"가격은 어느 정도 대충 정하고 가기 때문에 자기 한테 맞는 디자인인지가 가장 중요해요."(참여자 3)

"예복은 가끔 입는 옷이라 자기에게 맞는 편안하 고 격식에 맞는 디자인의 옷을 찾게 되는 옷을 사 게 되고, 평상복은 가격 대비 가성비가 중요하고, 입어서 편한지 등을 따져보게 돼요. 그리고 쉽게 세탁이 가능한지, 다른 옷과의 매치가 가능한지를 고려하게 됩니다."(참여자 4)

\section{4) Shopping channel}

\section{○ 신뢰하는 상점, 신뢰하는 브랜드}

쇼핑 방식은 되도록 시간이 적게 들고 옷을 많이 입어 보지 않아도 되는 신뢰할 수 있는 상점을 통해 이루어지며, 인지도가 있는 브랜드를 선호하는 것으 로 나타났다. 제품에 대한 품질을 신뢰할 수 있는 백 화점이나 자주 다녀서 검증된 단골 매장을 주로 이용 하였다. 경우에 따라서는 옷을 사면서부터 코디네이 션을 하여 구매를 하고, 외출 시 입기 위해 양말까지 함께 세팅하여 준비하기도 한다고 하였다. 이러한 의 복행동도 신뢰라는 측면이 강조되어 여러 여건상 선 택의 폭이 넓지 않기에 되도록 시행 착오를 적게 겪 기를 원하기 때문인 것으로 보여진다.

“저는 감촉이 좋은 옷을 좋아해요. 그런데 감촉이 좋고 핏이 좋은 옷은 비싸더라구요. 그런데 저는 남대문 시장과 같은 곳에서 여러 번 옷을 입고 벗 고 하는 게 힘들기 때문에 돈을 조금 더 주더라도 백화점과 같은 곳에서 사게 됩니다. 더군다나 함께 갈 사람을 섭외하는 것도 힘듭니다."(참여자 5)

\section{과도한 패션 수식어에 대한 거부감}

시각 장애인들이 직접 매장을 방문하는 쇼핑이 아 닌 홈쇼핑이나 인터넷, 점자 카탈로그와 같은 쇼핑 채널의 이용에 대해 질문한 결과, 이 역시 직접 매장
을 방문하지 않는다고 하더라도 다른 이의 도움이 필 요하다고 응답하였다. 주로 쇼핑 호스트들이 언어를 통해 제품을 설명하는 홈쇼핑은 시각 대신 청각으로 정보를 수집하는 시각 장애인에게 도리어 쇼핑 호스 트들의 과도한 외래어와 불필요한 전문용어의 사용 및 제품에 대한 마감 임박과 같은 구매 유도 등은 그 다지 유용하지 못한 쇼핑 방법이었으며, 경우에 따라 서는 거부감을 보이기도 하였다.

" $T V$ 홈쇼핑은 판매하는 사람들이 좋다고만 하고 가격만 이야기하고, 상품에 대한 구체적인 정보는 없어요."(참여자 1)

" $T V$ 홈쇼핑은 태반이 영어라 외국에서 살다온 사 람 같아요. 말 자체가 무슨 말을 하는 지 모르겠어 요."(참여자 2)

"쇼 호스트들에 대한 저는 불만이 많아요. 불필요 하게 단어들을 영어로만 설명하기 때문에 에휴, 그 말들은 전혀 도움이 안돼요. 무슨 말인지 몰라요." (참여자 4)

"예를 들면 그냥 접어서 입으세요 하면 되는 데 롤 업하세요 라고 하는 등 거부감 있고 전혀 도움이 안돼요."(참여자 5)

\section{위험 요소가 낮은 경우에만 온라인 구매}

인터넷 구매도 마찬가지로 타인의 도움을 받아야 했으며, 비교적 저렴한 가격이라는 장점을 가지고 있 으나, 직접 보고 고르지 않기 때문에 일어날 수 있는 위험성을 가지고 있어, 양말이나 속옷과 같이 가격이 저렴하고 크게 중요하지 않은 의류 품종이나, 이미 사용해 보아서 잘 아는 제품을 저렴하게 재구매할 때 사용하는 등 위험 요소가 적은 제품의 구매 시 주로 이용하는 것으로 나타났다.

"인터넷 쇼핑몰은 사이즈 등이 차이가 너무 나요. 브랜드마다 파는 곳마다 다르기 때문에 실패할 경 우가 많아요."(참여자 1)

"인터넷으로 하는 구매도 도움을 받아야 해요. 혼 자서는 할 수가 없습니다.”(참여자 2)

“인터넷은 양말이나 신발 등을 사요. 인터넷은 아 
무래도 가격이 싸기 때문에 구매를 하는 데 굳이 실패해서 반품하고 그런 번거로운 일을 하고 싶지 가 않아요. 인터넷으로 구매하는 경우에는 실패할 요소를 되도록 만들지는 않는 데, 인터넷으로 산 것이니까 그냥 감내하고 좀 맘에 안들어도 그냥 사 용해요."(참여자 3)

"인터넷에서 주는 정보만 가지고 구매하기에는 좀 부족해요. 직접 만져보고 사고 싶어요. 어쨌든 누 군가 봐줘야 구매를 해요. 내가 $100 \%$ 로 다 정보를 확인할 수 없기 때문이죠."(참여자 4)

“처음에 입어보고 신어 본 제품을 인터넷에서 좀 더 싼 가격으로 다시 구매하는 경우가 있어요. 디 자인과 모델명을 확실히 아는 경우에는 인터넷으 로 구매를 할 수 있어요."(참여자 5)

현재 출원되어 있는 특허인 시각 장애인들을 위해 점자를 이용한 홈쇼핑 카탈로그(Korea Patent No. $1020110132473,2011)$ 에 대해 연구대상자들에게 설 명을 하고, 이러한 시스템을 사용 의사가 있는 지에 대 해 응답자들은 시각 장애자를 위해 만든 홈쇼핑 카탈 로그지만, 이러한 점자를 통해 정보를 얻을 수는 있 겠지만, 이러한 점자 카탈로그도 시각이 온전한 누군 가와 함께 보고 구매의사에 도움을 주어야 구매가 가 능하다고 하였다.

“없는 것보다는 낫겠지만 그것을 누가 같이 보느 냐가 중요하죠. 같이 보는 사람이 괜창다고 사라고 하면 주문하겠지만, 혼자서는 그것도 보고 괜창은 지 아닌지를 판단해서 주문까지 하기는 힘들죠.” (참여자 2)

“사실 눈이 보이는 사람들도 인터넷이나 온라인으 로 쇼핑하고 구매하면서도 화면에서 보는 것과 직 접 보는 것이 다르고, 가서 입어봐야 하는데, 그 카 탈로그가 정보는 되겠지만 구매로 이어지기가 십 지 않죠."(참여자 4)

\section{Clothing behavior}

\section{○ 선택과 착용이 단순한 의복의 선호}

의복 생활에 있어 어려움은 색상과 디자인을 알기 어려워 상의와 하의의 옷을 맞추기가 가장 어려우며,
주변 사람들에게 도움을 받아 코디네이션을 해야 한 다고 응답하였다. 소유한 옷의 개수가 적거나, 디자인 등이 독특하다면 촉각을 함께 사용해 기억에 남을 확 률이 높겠지만, 옷의 개수가 적지 않고, 옷의 형태와 소재가 특징이 크지 않은 경우, 촉각만으로는 시각 장애인들이 기억하기 힘들다. 때문에 정장과 같이 옷 자체가 상하의 세트로 구성되어 있는 의복은 따로 코 디네이션을 하지 않아도 되기 때문에 선호하는 편이 며, 경우에 따라서는 매장에서 아예 코디네이션이 되 어 있는 옷을 그대로 사 오거나, 미리 옷을 준비해둘 때 함께 신을 양말까지 모두 세팅하여 옷걸이에 걸어 두고 필요시 꺼내 입기도 한다고 하였다. 짝을 맞추어 야 하는 속옷이나 양말과 같은 제품은 되도록 단순하 도록 같은 색과 디자인으로 구매하여 사용한다고 하 였다. 즉, 시각 장애인들은 본인 스스로 시각적으로 확인하기 힘든 의복생활의 문제를 해결하기 위해 되 도록 단순한 절차가 가능한 의복을 선택하고 착용하 는 것으로 보여진다.

“사람들이 만져보면 알지 않느냐고 합니다. 하지 만 디자인이 정말 특이하거나, 질감이 확실히 다르 거나 하면 알겠는데, 그것도 옷이 많지 않은 경우 에요. 그런데 디자인은 똑같거나 비슷하고 색상만 다르다거나 하면 잘 알기 어렵죠. 디자인이 한 두 가지도 아니고, 기본적인 옷의 종류는 알 수 있지 만, 그 이상은 옷을 만져서 다 알 수는 없기 때문에 한계가 있습니다."(참여자 1)

"색상을 맞추고, 상하의를 직접 맞추는 것은 제가 직접 하기는 힘들고, 정안인 즉 눈이 보이는 사람 의 도움을 받아야 해요. 옷이 어떤 질감과 무늬인 지를 기억해야 해요. 그런데 옷이 많으면, 시간이 지나면 까먹게 되지요. 그래서, 진한 색 계열은 옷 장의 오른 쪽에, 연한색은 왼쪽에 그런 식을 나누 기도 합니다."(참여자 2)

"제일 답답한 것은 색상을 모르는 거에요. 누가 없 으면 알 수가 없어요. 옷이 단순히 색상만 맞추어 서 되는 게 아니라, 디자인도 맞아야 하는 데 그게 어려워요. 오히려 정장은 편해요. 정장이 가장 편 해요. 정장은 색상이 맞추어져 있고, 어느 정도 정 장의 틀에서 벗어나지 않아요. 캐주얼은 어려워요. 
속옷이나 양말 같은 경우에는 짝짝이로 될 수 있어 서 마크나 디자인, 무늬들이 다르기 때문에 그런 일(짝짝이가 되는 일)을 피하기 위해서는 무늬가 없거나 단색으로 구매합니다."(참여자 3)

"내가 외우는 기본적인 색에 대한 개념 외에 다양 한 색이 너무 많아 그것을 다 알 수가 없어요. 그냥 외워서 무슨 색에 무슨 색을 입으라고 말하는 데 나의 얼굴의 색에 맞는 지, 나의 체형에 맞는 지 등 을 고려해야 하는 데, 그것이 제일 어려운 점이에 요. 그래서 나도 그렇고 내가 아는 주변의 시각 장 애인들도 대부분 어디에 입어도 무난한 색과 디자 인을 선호하는 편입니다."(참여자 4)

"안 보이지만 옷을 잘 입고 관심을 가지고 있는 시 각 장애인들이 많습니다. 그러나 실제적으로는 많 은 것을 고려해서 옷을 맞춰서 고르고 입는 것이 힘들죠. 그리고, 실명의 시기에 따라 색을 직접 보 고, 알고 있는 사람과 모르고 단순히 개념을 배워 서 외운 사람과는 많은 차이가 있어요."(참여자 5)

\section{○ 구매를 위한 정보탐색의 어려움과 정보원}

제품 구매시 어려운 점은 시각 장애인들에게 외출 자체가 쉽지 않았으며, 일반적으로 소비자들이 제품 을 구매하는 과정에서 지각되며 형성되는 내적 정보 의 양이 부족하다고 느끼고 있었다. 또한, 외적 정보 탐색의 양과 정보의 접근 가능성도 일반적으로 낮아 정보탐색활동이 제한적이었다. 그래서 주로 자신이 신 뢰하는 가족과 주변인으로부터 필요한 정보를 주는 정보원으로 활용하고 의존하는 특성이 있는 것으로 나타났다.

“경제적인 여건 등이 일반 사람들보다는 더 많이 소요됩니다. 일반 사람들은 밥 먹고 30 분 정도의 산책이 말 그대로 운동이고 산책이지만, 시각 장애 인들에게는 산책이란 개념이 거의 목숨을 내놓고 하는 일이라고 할 수 있습니다. 즉, 그래서 일반인 들이 손십게 한 10 분 정도 옷을 구경하고 쇼핑하 면 되는 일이 시각 장애인들은 1 시간 이상 소요되 는 일이 되고, 그 몇 배의 힘든 일을 하기는 쉽지 않 습니다."(참여자 1)

"모델링이 안돼요. 여건이 힘들어요. 축척되는 데이
터가 있잖아요. 즉, 인터넷 검색을 똑같이 해도 예 전에 실해했던 경험들이 쌍여서 색상이 실제로 이 정도는 다를 거야와 같은 예상을 하면서 실제 검색 을 하면서 나한테 어울리는 옷을 살 수도 있겠지만 불편한 부분이 너무 많습니다. 신경을 쓰고 싶어도 시간적으로 경제적으로 너무 힘들죠."(참여자 2)

"시각 장애인들이 마음에 드는 옷을 골라서 사 입 는 것도 마찬가지로 수 십배의 무언가를 감안을 하 고 하는 일이라고 할 수 있습니다."(참여자 3)

“선택의 여지가 별로 없죠. 함께 갈 사람을 골라야 하고, 시간도 내야 하고, 돈도 필요하고, 교통편도 정해야 하고, 많은 절차와 가변적인 요소가 너무 많아요."(참여자 5)

\section{Clothing management}

1) Dealing method of laundry and clothing custody ○ 직접 세탁관리하기에 부족한 정보

의복의 세탁관리는 스스로 수행 가능하지만, 세탁 관리에 필요한 정보의 제공이 부족하였다. 의복의 세 탁과 다림질 등의 관리는 주로 직접 하거나 동거인 이 하며, 관리법을 잘 모르는 경우 세탁소 등에 의뢰 하는 등 일반적인 세탁관리방법으로 이루어졌다. 그 러나 이 과정에서 가장 큰 어려움은 시각적 장애로 물세탁과 드라이 크리닝 등과 같은 기본적인 세탁방 법에 대한 정보를 혼자서 알기 힘들며, 세탁 전 세탁 물의 분류와 세탁 후 재분류가 어려움 점이 었다. 다 림질은 시각 장애인들을 대상으로 하는 일상 생활에 대한 훈련을 받아서 주변인의 도움을 받아 직접 다 림질할 수 있지만, 기본적으로 이 또한 주로 시각적 으로 제공되는 케어 라벨 등을 통해 확인해야 하므 로 시각 장애인이 스스로 확인하여 수행하기에 쉽지 않았다.

“세탁은 색상별로 분리해서 빨고 다시 색상별로 분 리하는 게 가장 힘들어요 다 섞여 버리니..."(참여 자 1)

"다림질은 기본적인 패턴 방법이 있어서 교육을 받 고 직접 할 수 있습니다. 교육을 받고 누군가 옆에 서 조금 도와주면 혼자 할 수 있습니다."(참여자 2) 
“세탁은 분리해서 빨고 마른 후에 다시 분리하는 게 힘들어요. 그래서 저는 빨래용 망을 이용해요. 망에 담아서 세탁을 하여 다시 분류할 수 있도록 해요."(참여자 4)

“저는 빨아서 말릴 때 양말과 같은 경우에는 아예 짝을 지어서 널어 말리고 짝지어진 그대로 걷어서 사용하거나, 세탁 후 옷걸이에 분류하면서 걸어서 보관하기도 해요."(참여자 5)

\section{2) Stain and laundry}

\section{$\bigcirc$ 오염물 확인의 어려움}

의복의 세탁 관리에 있어서는 오염원의 확인이 되 지 않아서 오염 여부나 오염의 정도와 무관하게 주기 적으로 세탁하는 경향이 있는 것으로 나타났다. 일반 적으로 의복의 세탁을 위해서는 오염을 확인하는데, 시각 장애인들이 의복의 더러운 정도를 인식하는 방 법은 스스로 인지하고 있는 오염원이나 냄새나는 오 염원들은 후각을 통해 판별할 수는 있다. 그러나, 오 염에 대한 인지가 불가능하거나 후각으로 알 수 없는 오염물이 있을 수 있으므로 일정한 기간이나 횟수를 정해놓고 그냥 세탁하는 편이었다. 이러한 잦은 세탁 은 시각 장애인들의 옷을 쉽게 닪아 헤지게 만들어 뿐 아니라, 미적, 경제적 측면의 손실을 가져왔다.

“국을 쏟거나 커피를 흘린다던가 내가 무언가가 묻 은 걸 알면 빨래를 할 텐데, $\cdots$ 다른 사람이 애기해 주지 않으면 뮈가 묻어 있는지 모르죠."(참여자 1)

"요즘엔 헤어져서 옷을 못 입는 경우가 별로 없다 는데, 시각 장애인들은 옷이 정말 헤어져서 못 입 는 경우가 많아요. 오늘 입었으면 굳이 더럽다 아니 다를 판단하지 않고, 그냥 빨아요. 그래야 혹시라 도 내가 모르는 이물질에 대비할 수 있죠. 그렁게 자주 빨다보니 옷이 금방 헤어져요."(참여자 2)

“그 부분이 제일 어려워요. 후각으로 냄새가 나면 알 수 있는데, 봄, 여름, 겨울에는 땀이 많이 나지 않으면 모르죠. 그리고 무언가 묻은 것을 알면 빠 는 데 알지 못하면 힘들어요."(참여자 3)

"제가 대충 날짜를 정해서 세탁을 해요. 그리고 주 변 사람들에게 무엇이 묻었는 지 물어보기도 하고 요."(참여자 4)
"짙은 색의 옷이나 하의는 비교적 가끔 세탁을 하고, 옅은 색이나 상의는 좀더 자주 세탁을 해요. 음식을 먹을 때 튀는 것은 주로 상의니까요."(참여자 5)

\section{Appearance management}

○ 존중받고 도움을 받기 위한 도구로서의 의복

시각 장애인들이 외모를 꾸미는 이유는 자신을 드 러내고 스스로에 대한 만족감과 타인에게 인정을 받 고 싶어 하는 사회심리적인 요인으로, 그 이면에는 자 신들을 보는 이들로 하여금 시각 장애인임을 감안하 여 보다 단정하고 깨끗하게 보여지기를 원하며, 이를 통해 타인이 가지는 시각 장애인에 대한 편견으로부 터 벗어나고, 존중받기를 원하는 것으로 해석된다.

"나는 내가 안보이지만 장애인에 대한 편견 때문 에 머리 염색도 할 때가 되었는지 주변 사람들에게 물어봐서 머리 염색을 해요."(참여자 1)

"기본적으로 누군가에게 잘 보이고 싶고, 자기의 위치를 나타내기 위해서이기 때문이죠. 그것은 누 구나 다 똑같겠죠." (참여자 2)

“사람들이 시각 장애인인기 때문에 옷을 후줄근하 게 입는다는 편견이 있는 것 같아 옷을 입을 때에 신경이 쓰여요."(참여자 3)

"보이는 사람이 옷을 입으면 그냥 그런가 보다 하 는데, 장애인이 옷을 좀 그렇게 입으면 아직도 우 리나라의 경우에는 편견이 있어서 모르고 입었나 보다, 장애인이니까 그렇게 입고 다니겠지라는 생 각을 기본적으로 깔고 가는 것 같아서, 깔끔하고 단정하게 입고 다니려고 해요."(참여자 4)

"옷을 신경 쓰면 너무 많은 것에 신경을 써야 하는 데, $\cdots$ 멋쟁이라고 하지 않더라도 기본적으로 욕을 안 먹을 정도로 단정한 정도로만 신경 쓰려고 합니 다."(참여자 5)

외모 평가에 있어 중요하게 생각하는 사람은 일차 적으로는 가족이었으며, 직장과 소속된 사회의 주변 사람들과 함께 여러 가지 활동 중에 만나게 되는 다 수의 사람들의 반응에 신경 쓰고 있었다. 시각 장애 인들이 믿을 수 있는 가족과 주변인들의 의견 외에도 자신이 알지 못하지만 자신을 보게 되는 불특정 다수 
의 사람들의 반응이 자신의 외모와 옷차림과 매우 밀 접하다고 느끼고 있으며, 이는 외모를 통한 자신이 누구인지에 대한 확장된 자아 개념(Park et al, 2013) 에 대한 것이라고 볼 수 있다. 즉, 비록 자신의 외모 를 스스로 볼 수 없다고 하더라도 자신을 표현하는 외모 관리를 통해 타인으로부터 존중받고 싶다는 심 리를 나타낸 것이라고 할 수 있다.

“저는 엄마와 옷을 사도 꼭 다시 동생에게 컨펌을 받아요. 사람들이 동생이 골라준 옷이나 매칭해준 옷차림에 칭찬을 해주기 때문에 내 스타일을 잘 알 고 있다고 생각해요. 그래서 동생과 함께 옷을 사 거나 다른 사람과 옷을 사도 동생에게 확인을 꼭 받아요." (참여자 1)

"사회생활을 위해서는 비장애인들하고 함께 있는 조직에 흡수되어 생활해야 하는 경우가 많은데, 시 각 장애인이라고 해서 이해해 주는 측면도 어느 정 도 있지만, 다른 사람들과 다르게 할 수는 없기 때 문에 옷차림을 매치하는 어려움을 해결하는 방법 의 하나로는 정형화되어 있는 정장과 같은 옷을 입 는 게 아무래도 사회생활을 하는 데 신경을 덜 쓸 수도 있고, 사회생활을 하는 데 많은 도움이 되어 개인적으로 선호하는 편하고 위험성이 적은 옷차 림입니다."(참여자 2)

“저는 의외로 외모에 신경을 많이 쓰는 편인데, 나 를 드러내기에도 그렇고, 일단은 도움을 받기에 용 이합니다. 잘 차려입은 사람에게 더 예의바릅니다. 지나가면서 툭 치고 지나가는 사람도 옷이 잘 입고 있으면 행동이 달라집니다. 고급 외제차를 건드리 지 않으려고 하는 것과 비슷하죠. 제가 제일 많이 느끼는 게 한국에서 시각 장애인을 보는 눈은 70 대 노인을 보는 눈과 비슷한 것 같아요. 그 둘을 보 는 위치가 같아요. 70 대 노인이라 해도 꾀죄죄한 노인을 보는 것과 잘 차려입은 노인을 보는 건 차 이가 있잫아요."(참여자 3)

“개인적으로는 나 자체도 나에게 신경을 많이 쓰 면 자신감이 생기고, 다른 사람들이 대하는 것 자 체가 다르다는 것을 느끼기 때문에, 조금이라도 옷 차림과 외모에 신경을 쓸 때 자존감도 높아집니 다."(참여자 4)
"요즘은 시선들이 트렌트에도 맞고 그런 옷을 입 었을 때 다른 사람들의 대우가 달라요. 시각 장애 인들은 길거리에서 만나는 많은 사람들에게 도움 을 요청하는 경우가 많은 데, 그럴 때 도움이 많이 됩니다. 그래서 어디 가서 면접을 보듯이 옷을 준 비하고 나갈 때가 많습니다.”(참여자 5)

\section{Conclusion}

본 연구는 시각 장애인들의 의복 생활에 대한 탐색 적 고찰을 시도함으로써, 그동안 시각적인 장애는 의 복 착용에 불편을 초래하는 신체적인 결함이 아니며, 이들의 시각적 인지와는 무관할 것이라는 편견 속에 서 이들을 위한 형태적인 디자인에 대한 연구나 미적 인 아름다움을 추구하는 연구 및 마케팅의 대상으로 고려되지 않았던 시각 장애인들의 의복 생활에 대해 이해하고자 하였다. 연구를 위해 시각 장애인들의 실 제적인 의복행동의 특성과 의복에 대한 시각 장애인 들의 태도를 알아보기 위해 심층 인터뷰를 통한 질적 연구 방법을 실시하며, 그 주요 결과를 요약하면 다 음과 같다.

첫째, 시각 장애인들은 의복 구매 시 옷에 대해 시 각적 인지와 쇼핑 장소로의 이동 등에 어려움이 있어 신뢰할 수 있는 사람과 동행하여 신뢰하는 상점과 브 랜드 제품을 주로 선호하는 것을 나타났다. 주로 가족 이나 친한 친구와 같은 가까운 이들을 신뢰하였으며, 제품의 품질을 보증할 수 있다고 믿는 백화점이나 브 랜드를 선호하고, 이전에 구매 경험을 바탕으로 제품 을 재구매하였다.

둘째, 시각 장애인들은 의복 제품의 구매와 사용을 위해 기본적인 상품 정보와 가장 단순한 절차를 통한 의복 선택 및 착용과 관리를 하였다. 시각 장애인들 은 의복 생활에 있어 색상과 디자인을 인지하기 어렵 기에 상하의가 세트로 구성되어 있거나, 이미 코디네 이션되어 있는 옷, 특별한 코디네이션 등이 필요하지 않은 옷 등의 시간이 적게 소요되고, 많이 입어 보지 않아도 되는 제품들을 선호하였다.

셋째, 시각 장애인들은 세탁과 관리를 스스로 할 수 있으나, 세탁과 관리를 위한 인지 가능한 정보의 제공이 부족하여 어려움을 겪고 있었다. 의복의 세탁 여부 결정을 위한 오염에 대한 정보, 세탁을 위한 세 
탁방법에 대한 정보, 세탁 전 세탁물의 분류와 세탁 후 재분류를 위한 정보, 세탁 후 관리 및 다림질 등을 위한 정보 등의 기본적 정보를 시각 장애인이 스스로 확인하여 수행하기에 쉽지 않았다.

넷째, 시각 장애인들은 외모관리를 통해 자신에 대 한 만족감과 타인으로부터 존중받고자 하는 심리적 요인이 반영되어 있는 것으로 나타났다. 시각 장애인 들은 시각 장애라는 사회적으로 불리한 조건에 처한 이들로 적극적인 이해와 관심이 필요하다. 따라서 이 들의 외모관리는 타인들에게 장애인에 대한 사회적 편견에서 벗어나 보다 적극적인 존중과 배려에 관여 한다고 볼 수 있다. 그럼에도 정안인보다 더 많은 시 간적, 경제적, 동행인 섭외 등으로 인해 외모관리의 어려움을 느끼고 있었다.

본 연구의 결과는 시각 장애인의 의복생활에 대한 기초조사를 위해 실시한 연구로 시각 장애인의 특성 상 제한점을 가지고 있어 소수의 시각 장애인을 대상 으로 하였기에 이를 시각 장애인 전체로 일반화하기 에 제한점이 있을 수 있다. 따라서, 본 연구의 결과를 바탕으로 양적 접근과 시각 장애의 정도 등에 따른 다 양하고 지속적인 후속 연구가 필요하다.

지금까지의 논의 결과를 통해 시각 장애인들의 자 립적인 의생활을 위한 복지 향상에 대한 함의와 실천 적 제언은 다음과 같다.

첫째, 시각 장애인들은 시각적 장애로 인해 의복의 구매와 착용에 있어 어려움을 겪고 있으나, 동행가능한 사람과 비용, 시간적 제한이 있으므로 이들의 의복 욕 구를 해소해 줄 수 있는 있는 신뢰성 있고 비용이 높지 않은 동반자와 상점, 상품의 제공이 필요할 것이다.

둘째, 시각 장애인들이 의복의 구매와 관리를 위해 서는 먼저 가장 기본적인 전보가 제공되어야 한다. 이 를 위해 과도하고 불필요한 정보가 아닌 가장 기본적 으로 필요한 정보만을 선별하여 적절한 방법으로 제 시할 필요성이 있다.

셋째, 시각 장애인들의 의생활에 있어 자신의 시각 으로는 스스로를 확인하지 못한다고 하더라도 의복 욕구가 존재하며, 타인의 시선과 이에 대한 평가를 주요하게 인식하고 있다. 따라서 이들의 기본적인 의 복 욕구 충족을 통한 삶의 질 향상을 위해 보다 다양 하고 적절한 의복 코디네이션에 대한 정보 제공 방법 을 모색해 볼 필요가 있겠다.
끝으로, 본 연구의 결과를 통해 시각 장애인의 의 복생활에 대한 인식을 새롭게 하고, 그동안의 편견과 한정적 접근 방식에서 벗어나, 시각 장애인들이 원하 는 진정한 자립적 생활 복지의 패러다임으로의 변화 를 위해 시각 장애인들의 의복욕구를 충족시켜 진정 한 의복생활의 자립으로 이어질 수 있도록 다양한 정 책적, 실천적 시사점이 제시되어야 할 것이다.

\section{References}

Ahn, J.-H., \& Lee, S.-J. (2007). A study on developing color braille system for the blind. Science of Emotion \& Sensibility, 10(4), 571-581.

Chong, H.-S., \& Lee, K.-R. (2011). A qualitative study on the disability experience of the handicapped with restricted growth. Social Science Research Review, 27(4), 265-289.

Giorgi, A. (2004). Phenomenology and psychological research (K. L. Shin, Y. G. Jang, I. S. Park, M. Y. Kim, \& S. E. Jung, Trans). Seoul: Hyunmunsa. (Original work published 1985)

Hong, S. S. (2001). Clothing for the handicapped: Brace $\cdot$ crutch \& wheelchair user. The Research Journal of the Costume Culture, 9(6), 830-841.

Kang, H. W. (1995). 의상사회심리학 [The social psychology of clothing]. Paju: Kyomunsa.

Kim, D. G. (2005). A study on the influential factors on the independent living of the people with visual impairment. Korean Journal of Social Welfare Research, 13, 83-110.

Kim, H. S., \& Rhee, E.-Y. (2008). Conceptualization and measurement of clothing needs and wants. Journal of Consumer Studies, 19(4), 1-18.

Kim, J. E. (2006). 소비자행동 [Consumer behavior]. Seoul: Hyungseul Publishing.

Kim, K.-A., \& Park, S.-K. (2005). A study on the development of clothes for the visually impaired: Focusing on the multi-functional design. Journal of the Korean Society of Fashion Design, 5(2), 15-29.

Kim, T. M., \& Choi, I.-R. (2011). A study of clothing attitude according to the self-esteem, body-cathexis 
and personal-relationship in multicultural families: Forcing on the chinese, filipinos and vietnamese. Journal of the Korea Fashion \& Costume Design Association, 13(4), 179-188.

Lee, H.-J. (2010). Wedding dress design for handicapped people. The Research Journal of the Costume Culture, 18(6), 1254-1260.

Lee, W.-S., \& Ye, K.-H. (2016). A study on the condition of the visually impaired in Korea. The Korean Journal of Vision Science, 18(3), 369-378. doi:10.17337/JMBI.2016.18.3.369

Lee, Y. S., \& Yoo, H. J. (2003). A study on fabrics and designs of clothing for handicapped persons. The Journal of Applied Science Technology, 12 (2), 1-11.

Merriam, S. B., \& Tisdell, E. J. (2015). Qualitative research: A guide to design and implementation (4th ed). San Francisco: John Wiley \& Sons.

Oh, I. P., Baek, A. R., Kwon, J. A., Park, H. J., Sohn, S. G., \& Choi, H. K. (2016, January). A study on improvement of assistive device for low vision: Focused on the use of smart assistive device and mobile application. Proceedings of HCI Korea, Jeongseon, 198-205. doi:10.17210/hcik.2016.01.198
Park, H. J. (2011). Korea Patent No. 1020110132473. Daejeon: Korean Intellectual Property Office.

Park, M. H., Park, M. S., Jae, M. K., Park, M. H., Jung, J. W., \& Choi, K. S. (2013). (가치소비시대 의) 소비자 의사결정 [Consumer values: How they affect consumer decision marking]. Paju: Kyomunsa.

Shin, E. H., \& Ohmi, G. (2012, May). Characteristics of color terms and their interrelationship in congenitally blind people. Proceedings of the Korean Society for Emotion and Sensibility Conference, Seoul, 13-14.

Shin, J.-S., Kim, I.-K., \& Choi, J.-W. (1999). An analysis of condition on clothing of disability. The Research Journal of the Costume Culture, 7(2), 304-314.

Shin, S. M., \& Chun, J. S. (2011). A study on donning and doffing independence of the person with disabilities on upper-limbs. The Research Journal of the Costume Culture, 19(1), 42-53.

Stake, R. E. (2001). 질적 사례연구 [The arts of case study research]. (Y. H. Hong, K. J. Roh, \& J. H. Shim, Trans.). Seoul: Chang-Ji Co,. Publishers. (Original work published 1995) 